\title{
Corrosion Protection of AA2024-T3 by Cerium Malate and Cerium Malate-Doped Sol-Gel Coatings
}

\author{
Tian-Hui Hu${ }^{1,2} \cdot$ Hong-Wei Shi ${ }^{2} \cdot{\text { Tao } \mathrm{Wei}^{2} \cdot \mathrm{Shi}-\mathrm{Hua} \mathrm{Fan}{ }^{1} \cdot \mathrm{Fu}-\mathrm{Chun} \mathrm{Liu}^{2} \cdot \text { En-Hou Han }}^{2}$
}

Received: 26 August 2018/Revised: 15 October 2018/Published online: 19 November 2018

(C) The Chinese Society for Metals and Springer-Verlag GmbH Germany, part of Springer Nature 2018

\begin{abstract}
Cerium malate (CeMal) was tested as a corrosion inhibitor for AA2024-T3 in this work. Corrosion inhibition on bare AA2024-T3 indicated that the inhibiting effect was a result of the synergistic effect of cerium cations and maleic anions. The corrosion of AA2024-T3 was stagnated by greatly reducing the corrosion current when CeMal was present in $\mathrm{NaCl}$ solutions. CeMal was adsorbed on the surface of AA2024-T3 forming a protective film in the initial stage. Then, cerium cations transformed to cerium oxide/hydroxides, precipitating on the cathode sites to inhibit the further corrosion. The electrochemical impedance spectra results of the sol-gel coatings proved that CeMal was an effective corrosion inhibitor in the sol-gel coatings to provide corrosion protection for AA2024-T3.
\end{abstract}

Keywords AA2024-T3 - Corrosion inhibitor - Sol-gel coatings · Scanning vibrating electrode technique (SVET) Electrochemical impedance spectroscopy (EIS)

\section{Introduction}

AA2024-T3 has been extensively used in aircraft industries. However, the alloy is susceptible to localized attack in aggressive environment, resulting in pitting, intergranular corrosion and stress corrosion cracking $[1,2]$. Traditionally, corrosion inhibitor has been widely used as an effective control method against corrosion of metals and alloys [3-10]. For many years, corrosion protection of aluminum alloys has relied extensively on chromate-based inhibitors by forming protective films on aluminum alloys or acting as inhibitor pigments in coatings [11]. In recent years, new effective corrosion inhibitors have been in great demand to replace the chromate-based inhibitors because of their high toxicity and environmental impact $[12,13]$. Environmentally compliant cerium salts have attracted the

Available online at http://link.springer.com/journal/40195

Hong-Wei Shi

hwshi@imr.ac.cn

1 Department of Chemistry, Northeastern University, Shenyang 110819, China

2 CAS Key Laboratory of Nuclear Materials and Safety Assessment, Institute of Metal Research, Chinese Academy of Sciences, Shenyang 110016, China interest of many researchers. Since the pioneering study of $\mathrm{CeCl}_{3}$ started by Hinton et al. on AA7075 in chloride solution [14], various cerium salts have been studied on corrosion inhibition of aluminum alloys [15, 16]. Cerium cations exhibited good role in the inhibition of AA2024-T3 [17]. It is well accepted that $\mathrm{Ce}^{3+}$ and $\mathrm{OH}^{-}$in the cathodic areas can form precipitates which inhibit the cathodic reaction of oxygen reduction, and moderately hinder anodic dissolution [18]. Cerium-containing inhibitors are potential alternatives of chromates and possibly provide comparable corrosion protection as chromates.

For protection of AA2024-T3, in addition to the use for bare alloy, cerium-containing inhibitors are also expected to be used as additives in the coatings [19, 20]. Usually, the solubility of these additives is low so that they can be directly added in organic or sol-gel coatings to enhance the barrier effect of coatings [21, 22]. Once electrolyte penetrates through the coatings, the released cerium cations or anions will reach the substrate surface accompanying the electrolyte, inhibiting corrosion of the substrate. So, the design of cerium-containing inhibitors with proper solubility is of quite importance. The cerium-containing inhibitors can be obtained by combination of cerium cations and some anions [3, 23-25]. Forsyth et al. [24] compared the inhibition effect of cerium salicylate (CeSal) with that of $\mathrm{NaSal}$ and $\mathrm{CeCl}_{3}$ for mild steel. It has been reported that 
cerium dibutylphosphate may offer a combined effect as a result of deposition of cerium oxide on the cathodic sites and adsorption of dibutylphosphate on AA2024-T3 surface with no preferential deposition [25]. For synthetizing organic cerium salts with low solubility, the crucial point is the choice of organic anions.

In our previous work, cerium tartrate (CeTar) and cerium cinnamate (CeCin) were proved to be effective corrosion inhibitors for AA2024-T3 [26, 27]. Cerium cations offered the overall anti-corrosion property, and the combination of cerium cations and carboxyl anions provided the proper solubility [28, 29]. However, a wider range of organic cerium salts is still needed for the protection of AA2024-T3. In the present work, a new organic carboxyl cerium salt, cerium malate (CeMal), was used as an inhibitor for AA2024-T3. It is expected to offer improved and effective corrosion inhibition on AA2024-T3 by the synergistic effect of cerium cations and maleic anions. Moreover, the solubility of CeMal powder is $6 \mathrm{mmol} / \mathrm{L}$, which is close to strontium chromate $(5.5 \mathrm{mmol} / \mathrm{L})$. So, it is expected to use CeMal in sol-gel coatings, and then in organic coatings in the future. The effect of corrosion inhibition provided by CeMal on bare AA2024-T3 was studied. CeMal was loaded in silane-based sol-gel coatings on AA2024-T3, and the corrosion resistance of the sol-gel coatings was analyzed.

\section{Experimental}

\subsection{Preparation of Materials and Solutions}

The substrate was AA2024-T3 (wt\%, Cu 4.54, Mg 1.51, Mn 0.63, Si 0.06, Fe 0.13, Zn 0.08, Ti 0.03 and Al bal.). Sheets with a dimension of $10 \mathrm{~mm} \times 20 \mathrm{~mm} \times 2 \mathrm{~mm}$ were prepared. The surface of each sheet was abraded by incrementally finer silicon carbide paper from $400^{\#}$ up to $2000^{\#}$. The electrode samples were cut from the above bare AA2024-T3 sheet and mounted in epoxy resin with a copper wire connected to the back side of the sample.

The corrosion inhibitor, CeMal powder, was prepared by mixing sodium malate ( $\mathrm{NaMal}$ ) with a little excessive cerium nitrate $\left(\mathrm{Ce}\left(\mathrm{NO}_{3}\right)_{3} \cdot 6 \mathrm{H}_{2} \mathrm{O}\right)$. All the chemicals were analytical reagent grade and purchased from Sinopharm Chemical Reagent Co., Ltd. The precipitate was obtained and filtered repeatedly with deionized water. Inductively coupled plasma atomic emission spectroscopy (ICP-AES) and brown ring test [30] were performed to check the residual $\mathrm{Na}^{+}$and $\mathrm{NO}_{3}{ }^{-}$in the filtrate. Then, the precipitate was dried at $50{ }^{\circ} \mathrm{C}$ for 1 day and stored in a desiccator for use. The powder was confirmed by Fourier transform infrared spectroscopy (FT-IR) [27]. The content of each element in the pure precipitate was detected by ICP-AES.
The analysis of ICP-AES showed that the moles ratio of $\mathrm{Ce}$ and $\mathrm{C}_{4} \mathrm{O}_{5} \mathrm{H}_{4}$ was 2:3. The solubility of CeMal detected by ICP-AES was c.a. $6 \mathrm{mmol} / \mathrm{L}$ in the distilled water. The solubility of CeMal in $0.05,0.01$ or $0.005 \mathrm{~mol} / \mathrm{L} \mathrm{NaCl}$ solution was proved to be the same with that in distilled water.

The $\mathrm{NaCl}$ solutions with saturated inhibitor were obtained by dissolving supersaturated CeMal into 0.05, 0.01 or $0.005 \mathrm{~mol} / \mathrm{L} \mathrm{NaCl}$ solution. After stirring for $10 \mathrm{~min}$, the solutions were filtered to remove remaining undissolved CeMal. Moreover, $0.05 \mathrm{~mol} / \mathrm{L} \mathrm{NaCl}$ solution with $0.012 \mathrm{~mol} / \mathrm{L} \mathrm{CeCl}_{3}$ and $0.05 \mathrm{~mol} / \mathrm{L} \mathrm{NaCl}$ solution with $0.018 \mathrm{~mol} / \mathrm{L} \mathrm{NaMal}$ were prepared for studying the synergistic effect of cerium cations and maleic anions.

\subsection{Preparation of the Sol-Gel Coatings}

The inhibitor was incorporated into silane-based sol-gel coatings to assess the protective properties. Three sol-gel coatings, one without CeMal, one doped with saturated CeMal and the other one doped with excessive CeMal $(6.5 \mathrm{~g})$, were prepared. The coated samples are denoted as reference, S-CeMal and E-CeMal.

The preparation process of the sol-gel coatings is as follows. $8.9 \mathrm{~mL}$ tetramethoxysilane (TMOS) and $42.8 \mathrm{~mL}$ 3-glycidoxypropyltrimethoxysilane (GPTMS) were mixed in $64.8 \mathrm{~mL} 0.05 \mathrm{~mol} / \mathrm{L}$ acetic acid solution $(0.05 \mathrm{~mol} / \mathrm{L}$ acetic acid solution, $0.05 \mathrm{~mol} / \mathrm{L}$ acetic acid solution with saturated CeMal, or $0.05 \mathrm{~mol} / \mathrm{L}$ acetic acid solution with excessive $6.5 \mathrm{~g} \mathrm{CeMal)}$ and then hydrolyzed. Each mixed solution was stirred for 3 days in a sealed breaker. After the hydrolysis of the two precursors in the mixed solution, $113.4 \mathrm{~mL}$ distilled water was added. Then, $4 \mathrm{~mL}$ crosslinking agent, diethylenetriamine, was added to the silane solutions. The above solutions were stirred thoroughly and allowed for about $10 \mathrm{~min}$ for the solution to settle down. Then, the AA2024-T3 sheets or electrode samples were dip-coated with the above steady solutions by a dip coater at a withdraw speed of $10 \mathrm{~cm} / \mathrm{min}$. Finally, the coated samples were cured in an oven at $100{ }^{\circ} \mathrm{C}$ for $10 \mathrm{~h}$.

\subsection{Immersion Tests}

For bare AA2024-T3, inhibition effect can be studied through immersion tests. The surface of two AA2024-T3 sheets was abraded to $7000^{\#}$. After rinsing with distilled water, the samples were immersed in $0.05 \mathrm{~mol} / \mathrm{L} \mathrm{NaCl}$ solutions with or without saturated CeMal for 1 day. Then, the two samples were observed by scanning electronic microscope (SEM) with the accelerating voltage of $20 \mathrm{kV}$.

For sol-gel coatings, the surface of reference, S-CeMal and E-CeMal samples before immersion and after 3 days 
of immersion in $0.005 \mathrm{~mol} / \mathrm{L} \mathrm{NaCl}$ solution was also observed by SEM.

\subsection{Electrochemical Measurements}

\subsubsection{Potentiodynamic Polarization}

Potentiodynamic polarization measurements were carried out on bare AA2024-T3 separately in $0.05 \mathrm{~mol} / \mathrm{L} \mathrm{NaCl}$ solution, $0.05 \mathrm{~mol} / \mathrm{L} \mathrm{NaCl}$ solution with $0.018 \mathrm{~mol} / \mathrm{L}$ $\mathrm{NaMal}, 0.05 \mathrm{~mol} / \mathrm{L} \mathrm{NaCl}$ solution with $0.012 \mathrm{~mol} / \mathrm{L} \mathrm{CeCl}_{3}$ and $0.05 \mathrm{~mol} / \mathrm{L} \mathrm{NaCl}$ solution with saturated CeMal. The concentration of $0.05 \mathrm{~mol} / \mathrm{L}$ was optimized to compare the inhibition effect of cerium cation, maleic anion or CeMal. The equipment used for electrochemical tests was EG\&G 273 Potentiostat/Galvanostat and EG\&G 5210 lock-in amplifier connected to a PC computer. In the polarization test system, a three-electrode cell was used. The saturated calomel electrode (SCE), platinum foil electrode and the electrode samples were used as reference, counter and working electrodes, respectively. The scan rate and potential range were $0.5 \mathrm{mV} / \mathrm{s}$ and $-0.6 \mathrm{~V} / \mathrm{SCE} \sim+1.0$ $\mathrm{V} / \mathrm{SCE}$ with respect to the $E_{\mathrm{ocp}}$, respectively. Three parallel tests were performed to confirm the repeatability.

\subsubsection{Electrochemical Impedance Spectroscopy (EIS)}

For bare AA2024-T3 samples, EIS was carried out in naturally aerated $0.05 \mathrm{~mol} / \mathrm{L} \mathrm{NaCl}$ solutions with or without saturated CeMal. The frequency range was from $100 \mathrm{kHz}$ to $10 \mathrm{mHz}$ with $10 \mathrm{mV}$ amplitude perturbing signal. The working electrode was the same one used in the polarization measurements. The surface of bare samples was abraded successively up to $2000^{\#}$. Three parallel tests were used to ensure the repeatability.

For coated samples, EIS measurements were performed in $0.005 \mathrm{~mol} / \mathrm{L} \mathrm{NaCl}$ solution. The sol-gel coatings degraded fast in $\mathrm{NaCl}$ solutions with higher concentration, so $0.005 \mathrm{~mol} / \mathrm{L}$ was confirmed to be an appropriate concentration to perform EIS. The exposed area of each coated sample was $1 \mathrm{~cm}^{2}$. The setting of EIS tests was the same with that for bare samples. Three parallel tests were performed to ensure the repeatability.

\subsubsection{Scanning Vibrating Electrode Technique (SVET)}

The corrosion activities were studied by SVET on the surface of bare AA2024-T3. The sample sheet with a dimension of $10 \mathrm{~mm} \times 10 \mathrm{~mm} \times 2 \mathrm{~mm}$ was mounted in epoxy resin attached to a Teflon holder. The exposed area was about $3 \mathrm{~mm} \times 3 \mathrm{~mm}$, leaving the other area sealed by wax. The surface of the samples was abraded successively to $2000^{\#}$ before tests.
Before the measurements, the resistivity values of the solutions were first measured by a conductivity meter and input to the software (Sciencewares ASET program). Then, the Pt-Ir probe (Microprobe Inc.) was platinized to form a platinum black ball with a diameter of $30 \mu \mathrm{m}$ at the tip. The probe was positioned $100 \mu \mathrm{m}$ above the sample surface. The vibrating frequencies of the probe were $270 \mathrm{~Hz}$ and $870 \mathrm{~Hz}$ in $X$ and $Y$ directions, respectively. The ionic current densities were mapped on a $40 \times 40$ grid in $0.01 \mathrm{~mol} / \mathrm{L} \mathrm{NaCl}$ solutions with or without saturated CeMal. The concentration of $\mathrm{NaCl}$ solution was decreased to $0.01 \mathrm{~mol} / \mathrm{L}$ to discern the difference in current density. The time of acquiring each SVET data point was $0.6 \mathrm{~s}$.

\subsection{Surface Analysis}

\subsubsection{X-ray Photoelectron Spectroscopy (XPS)}

XPS measurements were carried out on the sample after immersion in $0.05 \mathrm{~mol} / \mathrm{L} \mathrm{NaCl}$ solution saturated with CeMal. Because of the limitation of SEM-EDS, XPS spectra of Ce $3 d$ and $\mathrm{Al} 2 p$ were recorded to find Ce, using an ESCALAB250 system from Thermo VG with Al Ka anode $(k=1486.6 \mathrm{eV})$, operated under $5 \times 10^{-10}$ mbar. XPS spectra were acquired with a pass energy of $50.0 \mathrm{eV}$ and a spot size of $500 \mu \mathrm{m}$.

\subsubsection{Attenuated Total Reflectance Fourier Transform Infrared Spectroscopy (ATR-FTIR)}

In order to explore the presence of organic maleic anion groups on the sample surface, ATR-FTIR was also used for the sample immersed in $0.05 \mathrm{~mol} / \mathrm{L} \mathrm{NaCl}$ solution saturated with CeMal. A Spectrum 400 (Perkin Elmer Co., USA) measurement system, fitted with a Universal ATR sampling accessory, was used for infrared spectroscopy.

\section{Results and Discussion}

\subsection{Corrosion Inhibition of Bare AA2024-T3 by CeMal}

\subsubsection{Immersion Tests of Bare AA2024-T3}

The protective effect of CeMal on AA2024-T3 was observed by SEM after the immersion tests. Pits and corrosion products were found on the surface of the AA2024T3 sample after 1 day of immersion in $0.05 \mathrm{~mol} / \mathrm{L} \mathrm{NaCl}$ solution, as shown in Fig. 1a. Figure $1 \mathrm{~b}$ shows the AA2024-T3 surface after 1 day of immersion in $0.05 \mathrm{~mol} /$ $\mathrm{L} \mathrm{NaCl}$ solution with saturated CeMal. There are no visible 

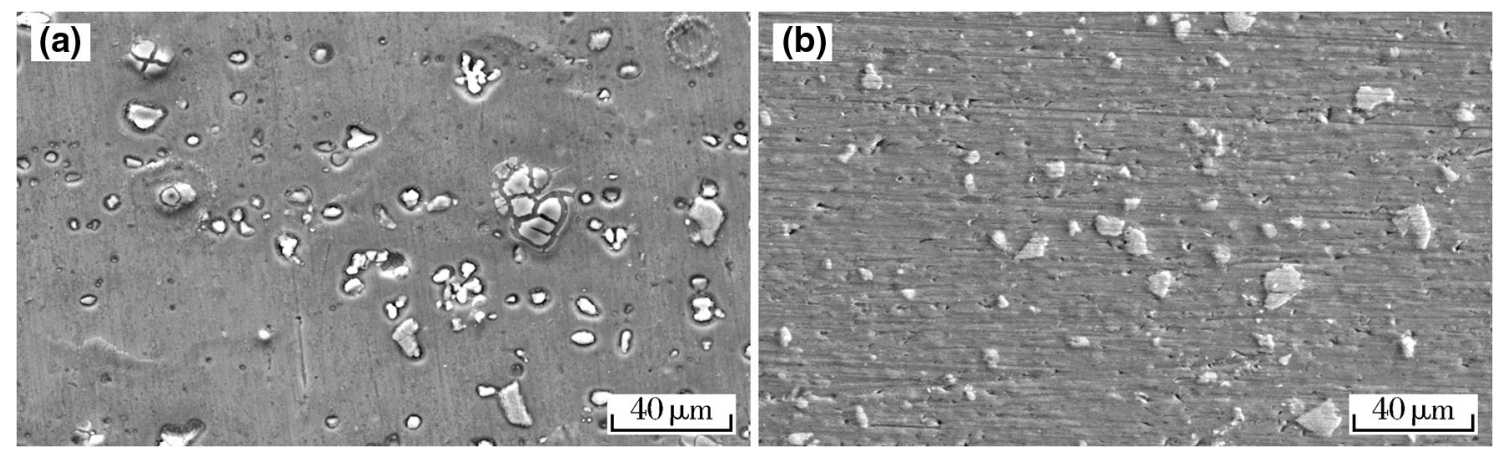

Fig. 1 SEM images of polished AA2024-T3 samples after 1 day of immersion in a $0.05 \mathrm{~mol} / \mathrm{L} \mathrm{NaCl}$ solution, b $0.05 \mathrm{~mol} / \mathrm{L} \mathrm{NaCl}$ solution with saturated CeMal

corrosion products. It shows that CeMal is effective in inhibiting corrosion of AA2024-T3.

\subsubsection{Synergistic Effect of Cerium Cation and Maleic Anion}

CeMal was developed following the approach of combination of cerium cations and carboxyl anions. It is expected that both cerium cations and maleic anions of CeMal contribute to the corrosion inhibition. Potentiodynamic polarization tests were performed to compare the individual inhibition effect of cerium cations, maleic anions and CeMal in $0.05 \mathrm{~mol} / \mathrm{L} \mathrm{NaCl}$ solution. Cerium cations and maleic anions were provided by $\mathrm{CeCl}_{3}$ and sodium malate (NaMal), respectively. The concentration of cerium cations or maleic anions was equal to that in the solution of CeMal. Anodic and cathodic parts of the curves were scanned separately. As shown in Fig. 2, the polarization curve of the sample immersed in blank $0.05 \mathrm{~mol} / \mathrm{L} \mathrm{NaCl}$ solution shows immediate pitting and the corrosion potential $\left(E_{\text {corr }}\right)$ is around $-0.54 \mathrm{~V}$. For the sample immersed in $0.05 \mathrm{~mol} /$ $\mathrm{L} \mathrm{NaCl}$ solution with $0.018 \mathrm{~mol} / \mathrm{L} \mathrm{NaMal}$, the current density is not reduced. The anodic part shows a large passive range of $0.5 \mathrm{~V}$ and a shift of the pitting potential

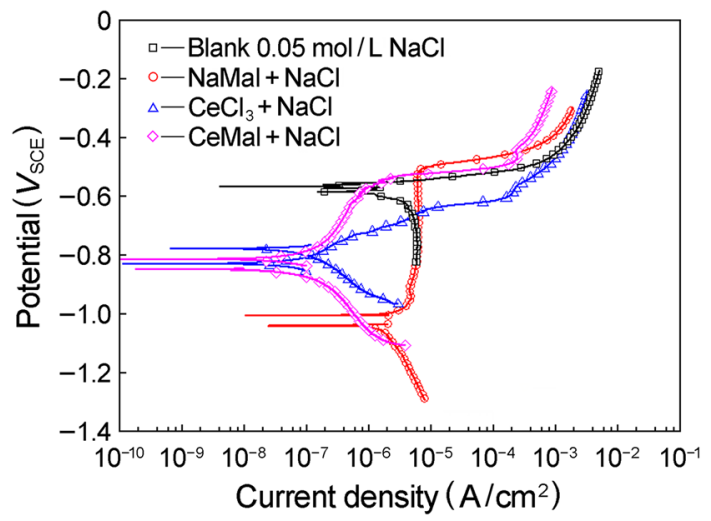

Fig. 2 Polarization curves for AA2024-T3 samples immersed in $0.05 \mathrm{~mol} / \mathrm{L} \mathrm{NaCl}$ solution, $0.05 \mathrm{~mol} / \mathrm{L} \mathrm{NaCl}$ solution with $0.018 \mathrm{~mol} /$ L NaMal, $0.012 \mathrm{~mol} / \mathrm{L} \mathrm{CeCl}_{3}$ or saturated CeMal
$\left(E_{\text {pit }}\right)$ to more noble values, indicating anodic inhibition [8]. It implies that NaMal can form adsorption film on the sample surface and maleic anion part can provide corrosion inhibition for AA2024-T3. For the samples immersed in $0.05 \mathrm{~mol} / \mathrm{L} \mathrm{NaCl}$ solution with $0.012 \mathrm{~mol} / \mathrm{L} \mathrm{CeCl}_{3}$ and $0.05 \mathrm{~mol} / \mathrm{L} \mathrm{NaCl}$ solution with saturated CeMal, the cathodic current densities were reduced by about one order of magnitude. The anodic polarization curves for the samples in the two solutions show the passive ranges. $E_{\text {pit }}$ of the sample immersed in $0.05 \mathrm{~mol} / \mathrm{L} \mathrm{NaCl}$ solution with saturated CeMal positively shift due to the presence of maleic anions, as compared with that of the sample immersed in $0.05 \mathrm{~mol} / \mathrm{L} \mathrm{NaCl}$ solution with $0.012 \mathrm{~mol} / \mathrm{L}$ $\mathrm{CeCl}_{3}$. The above results illustrate that cerium cations and maleic anions of CeMal in the solution worked synergistically. The film-forming ability of cerium cations was greatly enhanced by mixing with organic maleic anion part. This can be related to the adsorption ability of organic maleic anion group on the AA2024-T3 surface.

In order to further investigate the inhibition effect and mechanism of cerium cations and maleic anions of CeMal, AA2024-T3 sample immersed in $0.05 \mathrm{~mol} / \mathrm{L} \mathrm{NaCl}$ solution with saturated CeMal was characterized by XPS spectra of Ce $3 d$ and Al $2 p$ (Fig. 3) and ATR-FTIR (Fig. 4). In the case of Ce $3 d$ spectrum shown in Fig. 3a, there are four distinct characteristic peaks. The two main peaks at 883 and $902 \mathrm{eV}$ are characteristic peaks of $\mathrm{Ce}$ (III). The other two satellite peaks at 880 and $900 \mathrm{eV}$ are observed due to the existence of Ce(IV) [31]. The curve of Ce $3 d$ spectra indicated a mixture of oxide/hydroxide of $\mathrm{Ce}$ (III) on the surface of AA2024-T3. At the same time, the main Ce(III) peaks with much larger area suggested that $\mathrm{Ce}_{2} \mathrm{O}_{3} /$ $\mathrm{Ce}(\mathrm{OH})_{3}$ were the dominant species due to the change in $\mathrm{pH}$ at electrolyte/sample interface during the immersion. The formation of cerium oxide/hydroxide films can be described as follows:

$\mathrm{O}_{2}+2 \mathrm{H}_{2} \mathrm{O}+4 \mathrm{e} \rightarrow 4 \mathrm{OH}^{-}$, 

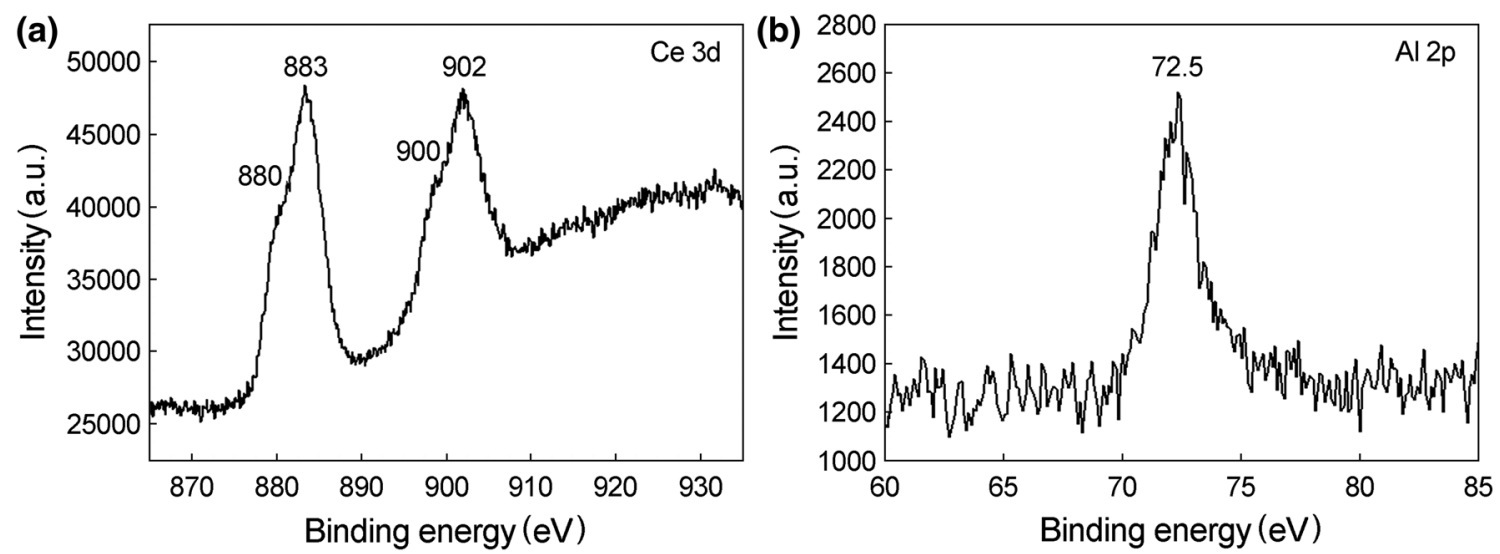

Fig. 3 XPS spectra of component a Ce $3 d$, b Al $2 p$ on the bare AA2024-T3 after $24 \mathrm{~h}$ of immersion in 0.05 mol/L NaCl solution with saturated CeMal
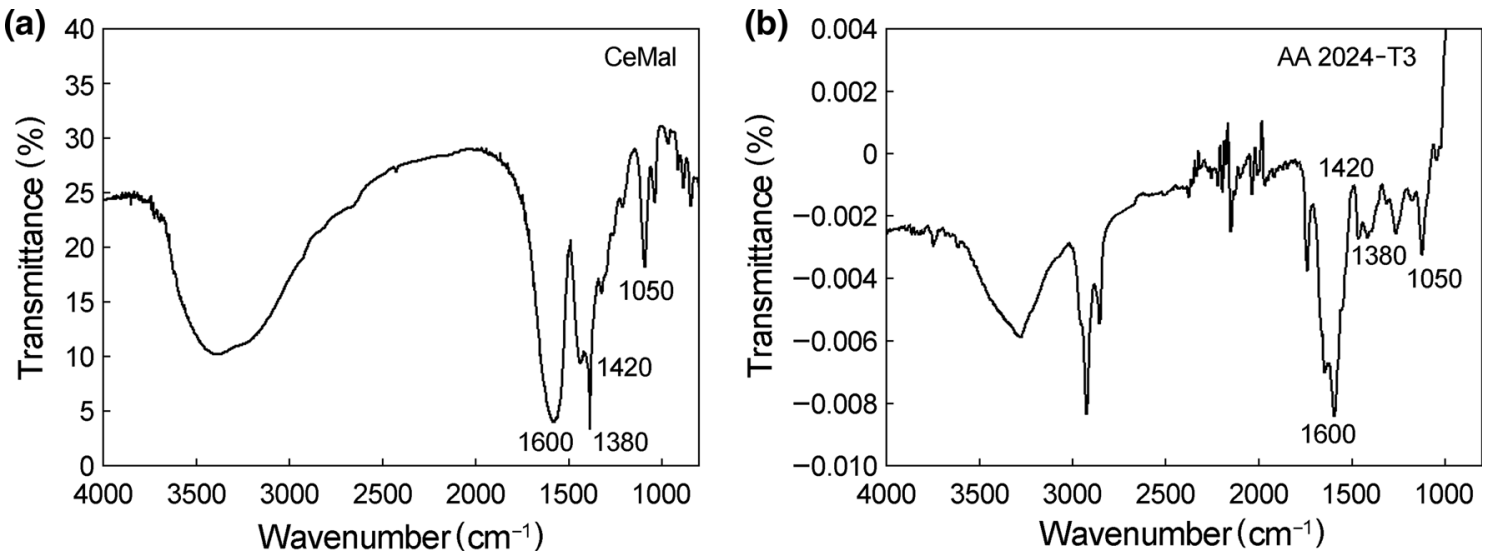

Fig. 4 FT-IR spectra of a CeMal powder and ATR-FTIR spectra of b CeMal on AA2024-T3 sample surface

$$
\begin{aligned}
& \mathrm{Ce}^{3+}+3 \mathrm{OH}^{-} \rightarrow \mathrm{Ce}(\mathrm{OH})_{3} \downarrow \\
& 4 \mathrm{Ce}^{3+}+\mathrm{O}_{2}+4 \mathrm{OH}^{-}+2 \mathrm{H}_{2} \mathrm{O} \rightarrow 4 \mathrm{Ce}(\mathrm{OH})_{2}^{2+}, \\
& \mathrm{Ce}(\mathrm{OH})_{2}^{2+}+2 \mathrm{OH}^{-} \rightarrow \mathrm{CeO}_{2} \downarrow+2 \mathrm{H}_{2} \mathrm{O} .
\end{aligned}
$$

Figure $3 \mathrm{~b}$ shows the curve of $\mathrm{Al} 2 p$ spectrum. The peaks at $72.5 \mathrm{eV}$ can be ascribed to $\mathrm{Al}$ matrix, indicating that there was no obvious corrosion on the surface of the sample [29].

FT-IR of CeMal powder and ATR-FTIR of film covered on aluminum alloy surface were recorded, as shown in Fig. 4. The characteristic bands from 1000 to $1700 \mathrm{~cm}^{-1}$ in the two spectra are similar. The peak around $1050 \mathrm{~cm}^{-1}$ belongs to $v(\mathrm{C}-\mathrm{OH})$. The absorption bands with peaks at $1600 \mathrm{~cm}^{-1}$, and at 1380 and $1420 \mathrm{~cm}^{-1}$ can be attributed to the presence of $v\left(\mathrm{COO}^{-}\right)$[32], indicating the existence of the organic maleic part of CeMal on the surface of AA2024-T3. Organic carboxylic groups can be adsorbed on the surface of aluminum alloy, forming adsorption film which can inhibit corrosion of aluminum alloy [3, 29]. In the case of CeMal in the solution, CeMal may first be adsorbed on the surface of AA2024-T3 to form adsorption film to block the adsorption and attack of chloride ions. Then, $\mathrm{Ce}^{3+}$ reacts with $\mathrm{OH}^{-}$upon onset of corrosion. This can form film on the alloy surface which inhibits the cathodic reaction.

The surface analysis revealed that the inhibition film on the bare AA2024-T3 was composed of cerium oxide/hydroxide and organic maleic groups, evidencing that both cerium cations and maleic anions of CeMal in the solution may contribute to corrosion inhibition.

\subsubsection{Inhibition Effect of CeMal by Electrochemical Tests}

The inhibition effect of CeMal on AA2024-T3 sample was further studied by polarization curves and EIS. Figure 5a shows the polarization curves of AA2024-T3 sample during immersion in $0.05 \mathrm{~mol} / \mathrm{L} \mathrm{NaCl}$ solution with saturated $\mathrm{CeMal}$ and $0.05 \mathrm{~mol} / \mathrm{L} \mathrm{NaCl}$ solution. The polarization curve of AA2024-T3 immersed in $0.05 \mathrm{~mol} / \mathrm{L} \mathrm{NaCl}$ solution with saturated CeMal shows a passive range (c.a. $200 \mathrm{mV}$ ) immediately after immersion $(0 \mathrm{~h})$. The current density shows a decrease as compared with that of the 

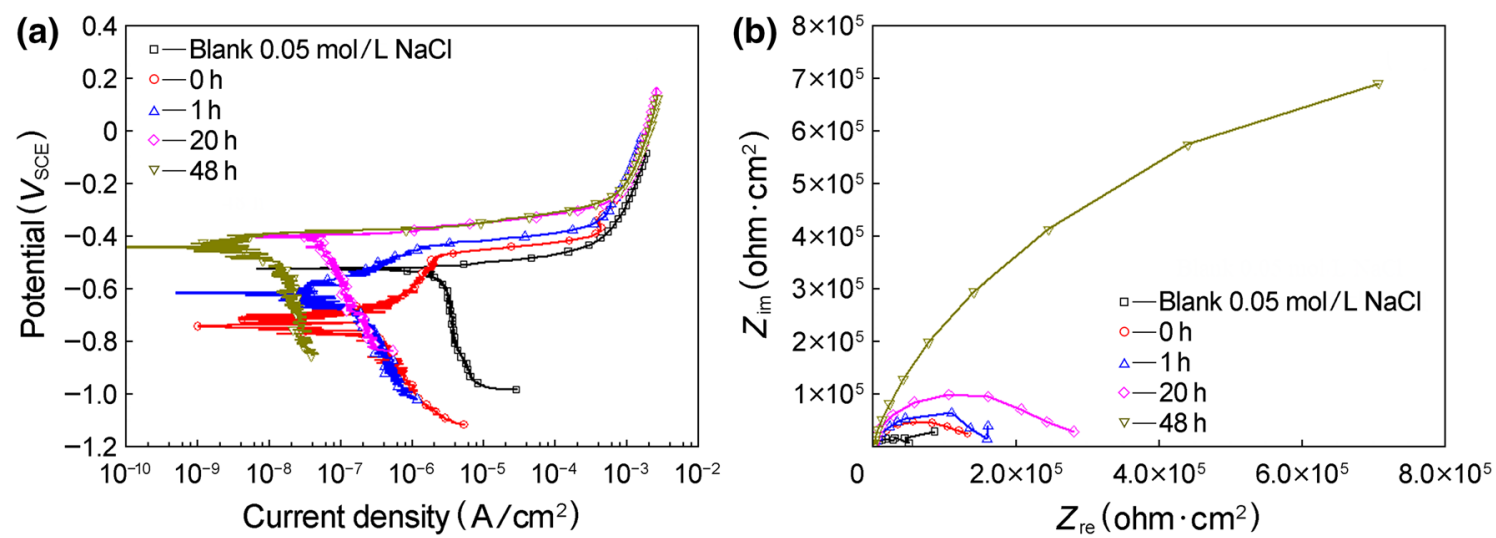

Fig. 5 Polarization curves for AA2024-T3 samples immersed in a blank $0.05 \mathrm{~mol} / \mathrm{L} \mathrm{NaCl}$ solution and $0.05 \mathrm{~mol} / \mathrm{L} \mathrm{NaCl}$ solution with saturated CeMal for different times, b Nyquist plot for AA2024-T3 sample immersed in blank $0.05 \mathrm{~mol} / \mathrm{L} \mathrm{NaCl}$ solution and $0.05 \mathrm{~mol} / \mathrm{L} \mathrm{NaCl} \mathrm{solution}$ with saturated CeMal for different times
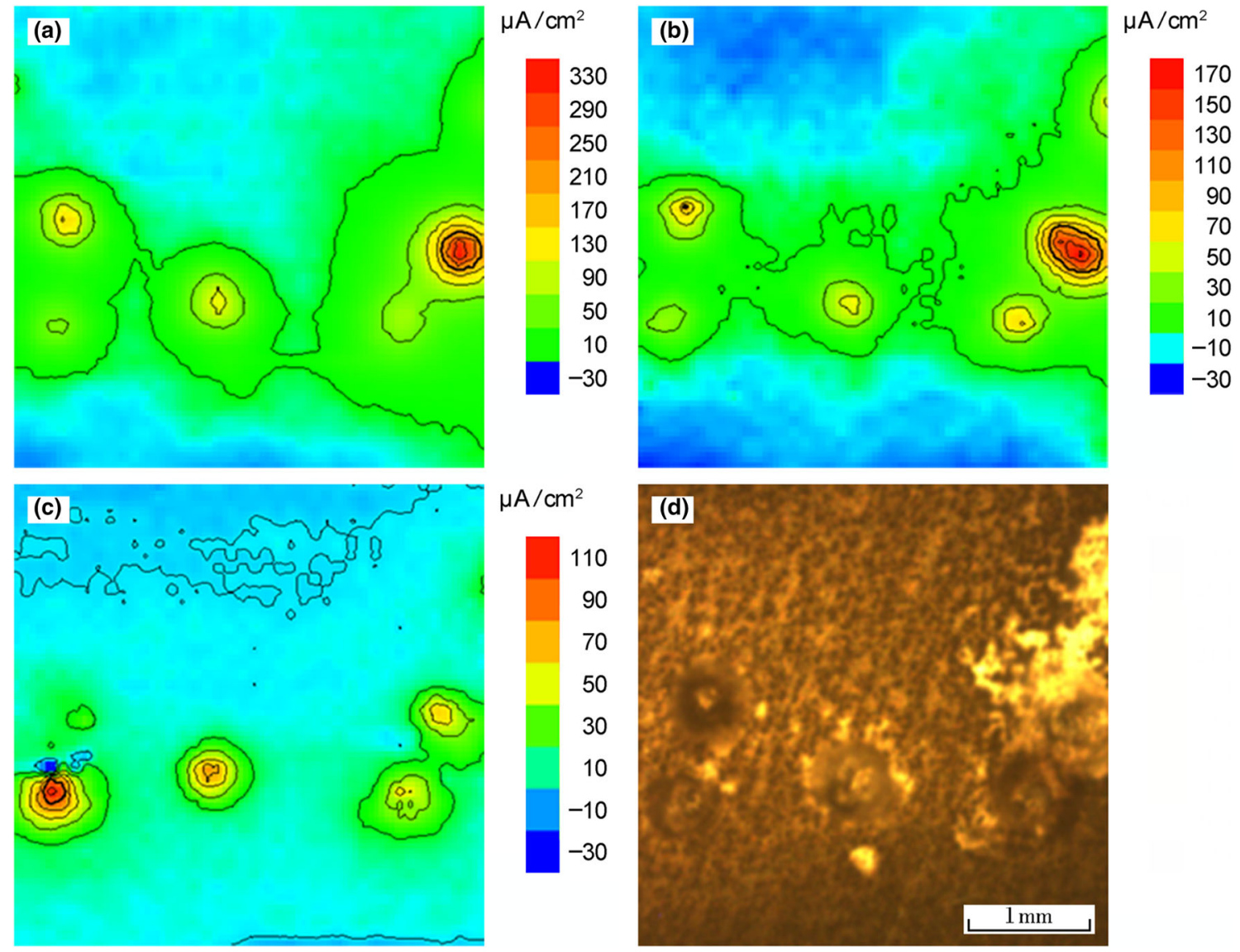

Fig. 6 SVET maps over the sample after a 0 h, b $10 \mathrm{~h}, \mathbf{c} 24 \mathrm{~h}$ of immersion, d optical photograph of bare AA2024-T3 after $24 \mathrm{~h}$ of immersion in $0.05 \mathrm{~mol} / \mathrm{L} \mathrm{NaCl}$ solution

sample immersed in $0.05 \mathrm{~mol} / \mathrm{L} \mathrm{NaCl}$ solution. Both anodic and cathodic inhibitions are evident for the sample immersed in $0.05 \mathrm{~mol} / \mathrm{L} \mathrm{NaCl}$ solution with saturated CeMal. The presence of CeMal produces a more negative potential $\left(E_{\text {corr }}\right)$ and a larger passive range, indicating the formation of deposited layer of CeMal or the insoluble protective layer as a result of the formation of cerium oxide/hydroxide. After immersion for $1 \mathrm{~h}$, the passive range in the polarization curve for the sample immersed in $0.05 \mathrm{~mol} / \mathrm{L} \mathrm{NaCl}$ solution with saturated CeMal becomes smaller (c.a. $150 \mathrm{mV}$ ) than that of the initial state $(0 \mathrm{~h})$. However, the current density was decreased, indicating that 
the inhibition was enhanced. After 20 and $48 \mathrm{~h}$ of immersion, the passive ranges become less obvious, and the current density was decreased. During the immersion period, a positive potential shift indicates the decrease in the oxidation rate of aluminum due to the formation of another form of protective layer. The anodic polarization curves show a shift of the pitting potential $\left(E_{\mathrm{pit}}\right)$ to more noble values. At the same time, the passive ranges become smaller and the cathodic current density decreases with increasing immersion time, which can be interpreted by a strong cathodic inhibition during the immersion period. From the above results, it can be assumed that CeMal acts as an inhibitor with mixed anodic and cathodic inhibition effects. The lower current densities, shifts in $E_{\text {corr }}$, the shifting of $E_{\text {pit }}$ to more noble potentials from the polarization curves indicate the effective and the continued inhibiting effect of CeMal [8].

EIS measurements enable to characterize the interface of metal/electrolyte with oxide or adsorption films that formed on the AA2024-T3 substrate when exposed to corrosive solution with and without inhibitor [33, 34]. The Nyquist plots of AA2024-T3 sample exposed to $0.05 \mathrm{~mol} /$
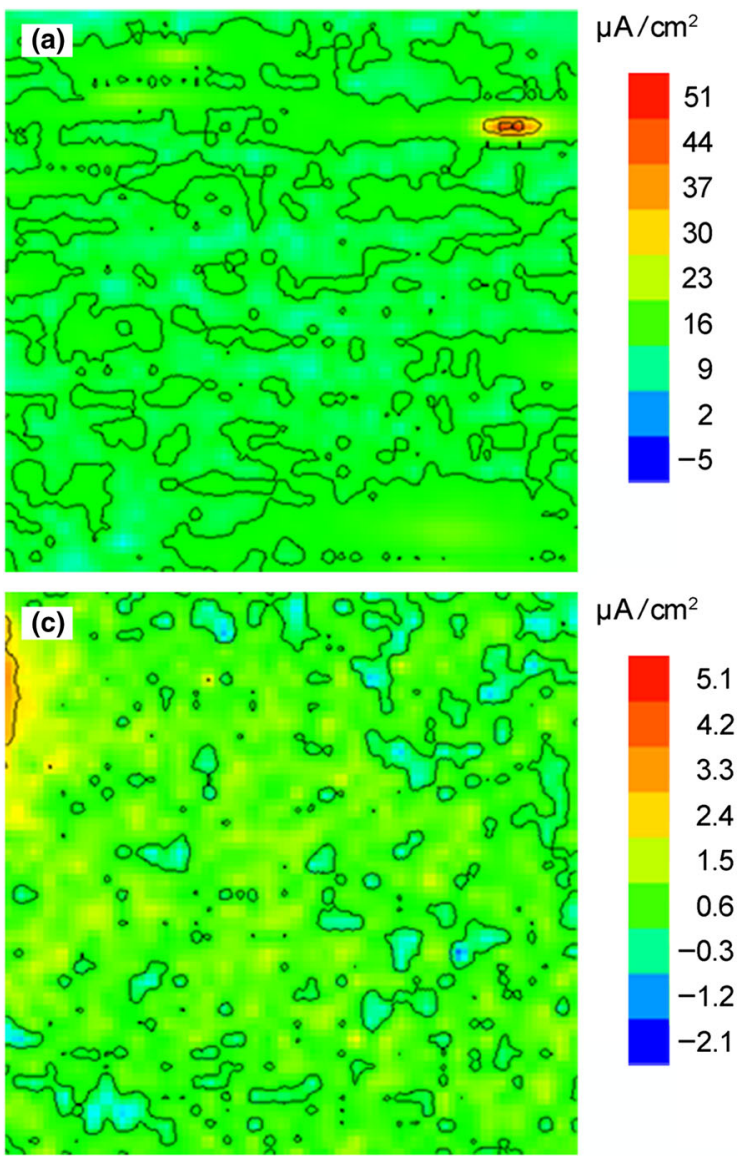

$\mathrm{L} \mathrm{NaCl}$ solution and $0.05 \mathrm{~mol} / \mathrm{L} \mathrm{NaCl}$ solution with saturated CeMal during $48 \mathrm{~h}$ of immersion are presented in Fig. 5b. The curve of the sample immersed in $0.05 \mathrm{~mol} / \mathrm{L}$ $\mathrm{NaCl}$ solution is shown with the smallest diameter of capacitive loop. The inhibiting effect of CeMal is characterized by the increase in diameter of capacitive loop during $0-48 \mathrm{~h}$, which suggests the continuous formation of a passive film containing CeMal on the sample surface. With the increase in immersion time, more cerium ions transformed to cerium oxide/hydroxides at cathodic sites. The growing rate of the precipitation film of cerium oxide/ hydroxides was faster than the destruction rate of deposition film of CeMal within $48 \mathrm{~h}$ of immersion. Therefore, the inhibiting effect of CeMal was enhanced with the increase in immersion time.

Corrosion of aluminum alloy is closely related to the magnitude of corrosion current. SVET is suitable to evaluate the effect of corrosion inhibitor. The inhibiting effect of CeMal was studied in a localized area of AA2024-T3 using SVET. Figure 6 shows the current densities and the photograph of the bare AA2024-T3 surface when exposed to $0.05 \mathrm{~mol} / \mathrm{L} \mathrm{NaCl}$ solution. Immediately after immersion
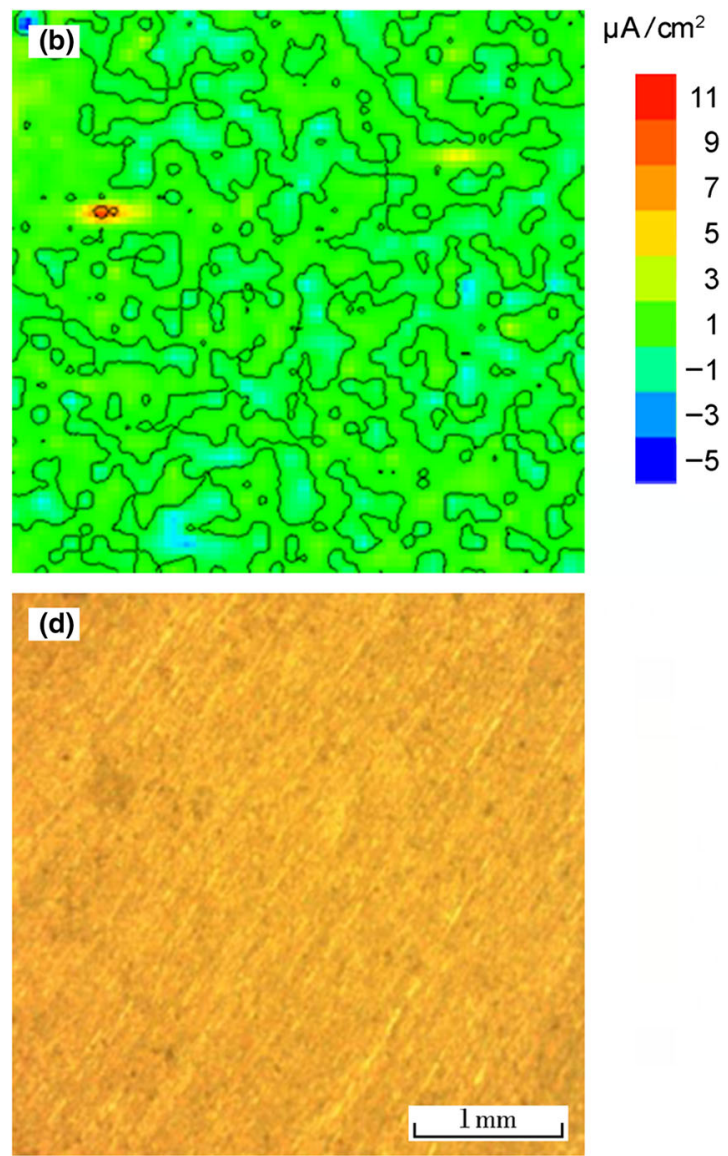

Fig. 7 SVET maps over the sample after a $0 \mathrm{~h}, \mathbf{b} 12 \mathrm{~h}, \mathbf{c} 24 \mathrm{~h}$ of immersion, d optical photograph of bare AA2024-T3 after $24 \mathrm{~h}$ of immersion in $0.05 \mathrm{~mol} / \mathrm{L} \mathrm{NaCl}$ solution with saturated CeMal 

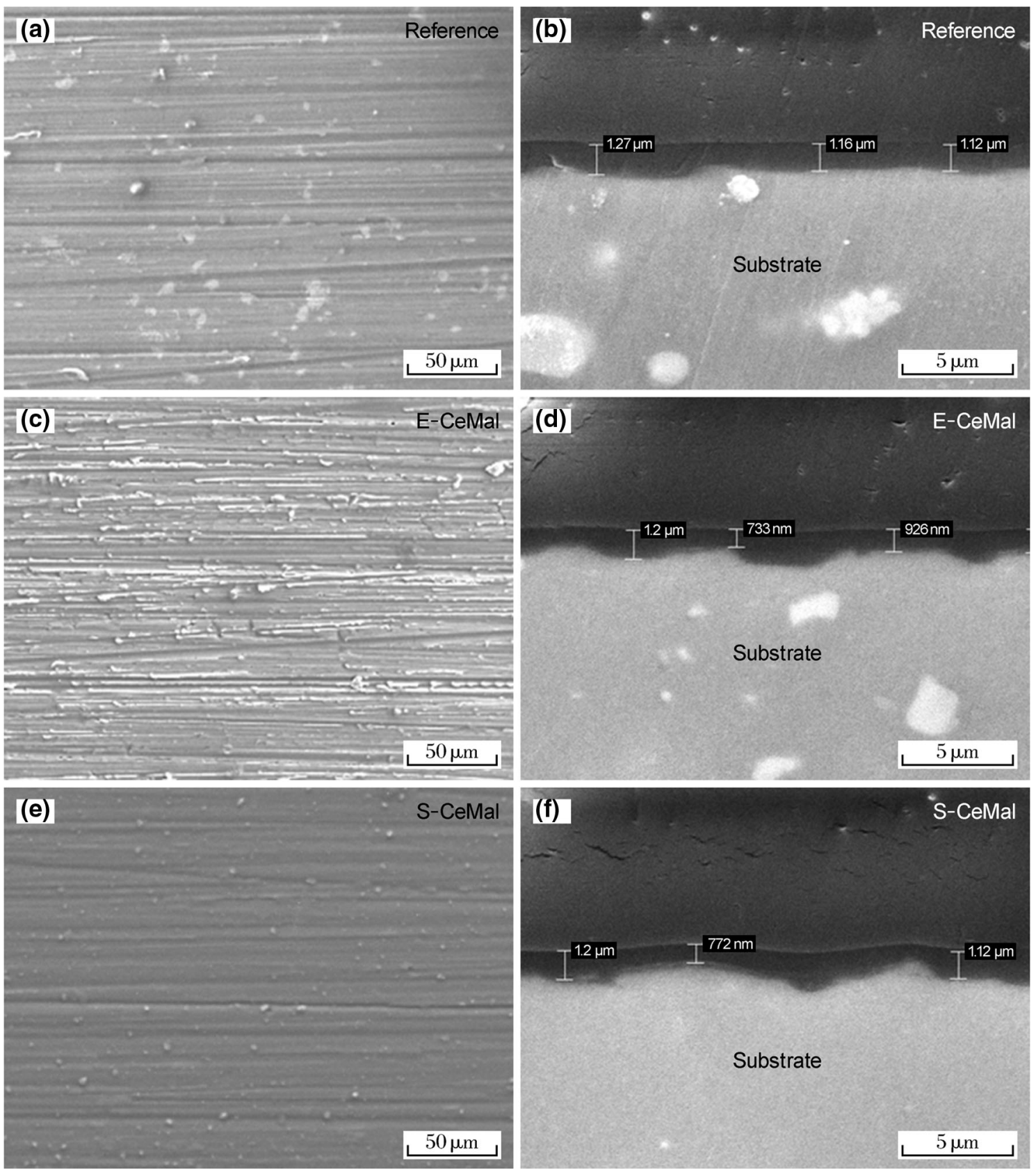

Fig. 8 SEM images of the surface of the samples coated with a reference, $\mathbf{c}$ E-CeMal, e S-CeMal sol-gel coatings, and cross section of the samples coated with b reference, d E-CeMal, f S-CeMal sol-gel coatings

$(0 \mathrm{~h})$, the striking anodic current peaks appear on the map (Fig. 6a). The maximum value of anodic current density is c.a. $330 \mu \mathrm{A} / \mathrm{cm}^{2}$. As the immersion time increased to $10 \mathrm{~h}$ (Fig. 6b) and $24 \mathrm{~h}$ (Fig. 6c), the maximum values of anodic current densities decrease, probably because the thick corrosion products have a blocking effect on the anodic reaction. As shown in Fig. 6d, corrosion products can be found on the sample after $24 \mathrm{~h}$ of immersion.

Figure 7 shows the current densities and the photograph of the bare AA2024-T3 surface when exposed to $0.05 \mathrm{~mol} /$
$\mathrm{L} \mathrm{NaCl}$ solution with saturated CeMal. The maximum value of anodic current density is c.a. $50 \mu \mathrm{A} / \mathrm{cm}^{2}$, and the maximum value of the cathodic current density is c.a. $-5 \mu \mathrm{A} / \mathrm{cm}^{2}$ immediately after immersion (Fig. 7a), which is much lower than the values of current density indicated in Fig. 6. Thereafter, the anodic current density shrinks continuously to c.a. $5 \mu \mathrm{A} / \mathrm{cm}^{2}$ as the immersion time increases (Fig. $7 \mathrm{~b}, \mathrm{c}$ ). The anodic reaction maintains at a very low level, which can be ascribed to the protective film due to the presence of CeMal. Moreover, much less 

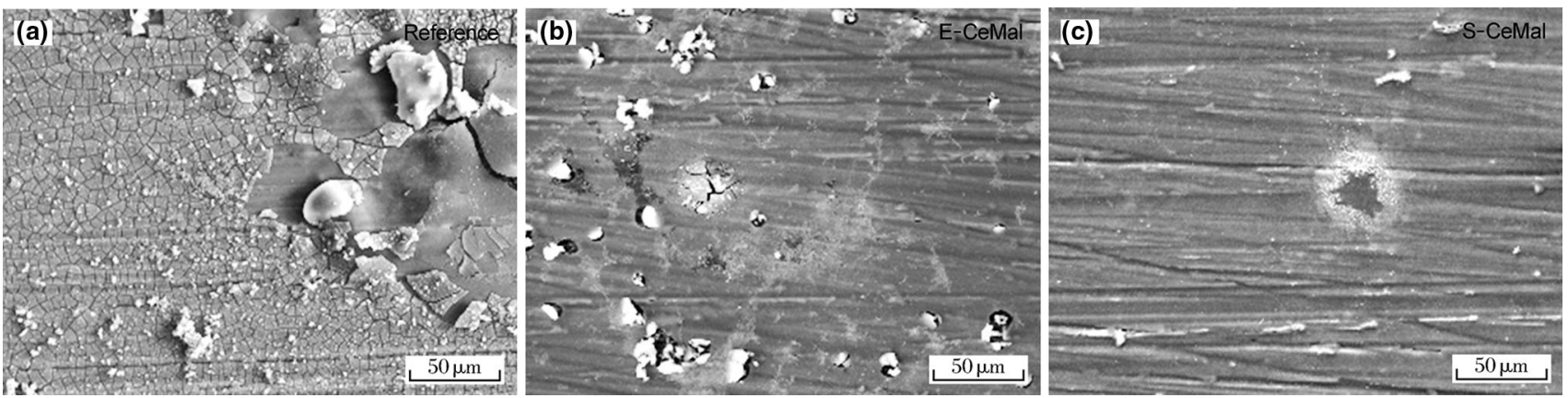

Fig. 9 SEM images of the surface of the samples coated with a reference, $\mathbf{b}$ E-CeMal, $\mathbf{c}$ S-CeMal sol-gel coatings after 3 days of immersion in $0.005 \mathrm{~mol} / \mathrm{L} \mathrm{NaCl}$ solution

corrosion products on the sample (Fig. 7d) were shown as compared to the sample immersed in $0.05 \mathrm{~mol} / \mathrm{L} \mathrm{NaCl}$ solution, confirming that the corrosion activities of AA2024-T3 were inhibited by CeMal.

\subsection{Corrosion Protection of CeMal-Doped sol-gel Coatings}

\subsubsection{Immersion Tests of the Sol-Gel Coatings}

The sol-gel coatings were first observed by SEM before and after immersion in $0.005 \mathrm{~mol} / \mathrm{L} \mathrm{NaCl}$ solution [35]. The typical surface and cross section morphologies of reference, E-CeMal and S-CeMal sol-gel coatings are displayed in Fig. 8a-f. All the sol-gel coatings show fluctuation along with the roughness of substrate resulting from the abrading process. The thickness of the sol-gel coatings is around $1 \mu \mathrm{m}$. After 3 days of immersion in $0.005 \mathrm{~mol} / \mathrm{L} \mathrm{NaCl}$ solution, the surface morphologies of the reference, E-CeMal and S-CeMal coatings are shown in Fig. 9a-c. The reference coating is degraded, demonstrating many cracks. Defects can be seen on the E-CeMal coating probably because of the dissolution of CeMal from the sol-gel matrix. The S-CeMal coating shows much less defects and cracks as compared to the reference and E-CeMal coatings, indicating the best corrosion resistance. Generally, the protective ability of the sol-gel coatings with inhibitor is better than those without inhibitor [36], but excessive addition may also reduce the protective performance of the sol-gel coatings [37].

\subsubsection{Corrosion Resistance of the Sol-Gel Coatings by EIS}

EIS was used to characterize the protective performance of CeMal in the sol-gel coatings. Figure 10 shows the Bode plots obtained on AA2024-T3 coated with reference, E-CeMal and S-CeMal sol-gel coatings during immersion in $0.005 \mathrm{~mol} / \mathrm{L} \mathrm{NaCl}$ solution. The impedance values of the samples coated with reference and S-CeMal sol-gel coatings at the low-frequency point $(0.01 \mathrm{~Hz})$ are similar in the beginning $(0 \mathrm{~h})$. Then, the impedance values of reference sample show a decrease from $24 \mathrm{~h}$ to $168 \mathrm{~h}$, and the $|Z|_{0.01 \mathrm{~Hz}}$ value is under $10^{5} \mathrm{O} \mathrm{cm}^{2}$ after $96 \mathrm{~h}$, implying weak protective ability of this coating. In contrast, the samples coated with E-CeMal and S-CeMal coatings have higher impedance values after $168 \mathrm{~h}$ of immersion, indicating effective protective ability.

For the above three coated samples immersed in $0.005 \mathrm{~mol} / \mathrm{L} \mathrm{NaCl}$ solution before $96 \mathrm{~h}$, two time constants are observed. The time constant in the high-frequency range is ascribed to the capacitance of sol-gel coating, and the other time constant in the low-frequency range is ascribed to the capacitance of the $\mathrm{Al}$ oxide or $\mathrm{Ce}$ oxide/ hydroxide layer $[38,39]$. The compactness and integrity of the $\mathrm{Ce}$ oxide/hydroxide layer can provide more effective protection than the native $\mathrm{Al}$ passive oxide layer [7, 40]. For the reference sample, after immersion for $96 \mathrm{~h}$, a new third time constant at low frequencies can be assigned to the double layer capacitance due to corrosion of AA2024T3.

The equivalent electric circuits (EEC) used for fitting EIS data are shown in Fig. $11 \mathrm{a}$, b. In the EECs, $R_{\mathrm{s}}, R_{\mathrm{c}}, R_{\mathrm{o}}$ and $R_{\mathrm{ct}}$ are the resistances of corrosive solution, sol-gel coating, oxide layer and charge transfer process on AA2024-T3, respectively. Due to the deviation of the capacitance in the EEC with pure capacitor, constant phase elements (CPE) are used to replace the pure capacitor with the symbols of $Q_{\mathrm{c}}, Q_{\mathrm{o}}$ and $Q_{\mathrm{dl}}$. The fitted values are listed in Table 1. At the beginning, the EIS plots of the three samples are fitted with EEC in Fig. 11a. After $96 \mathrm{~h}$ of immersion, three time constants appear on the EIS plots of reference sample. EEC in Fig. $11 \mathrm{~b}$ can be used to fit EIS data. At the same time, the increase in $Q_{\mathrm{c}}$ and $Q_{\mathrm{o}}$ values of reference sample indicates the failure of sol-gel coating and metal oxide film. After immersion for $96 \mathrm{~h}$, AA2024T3 was corroded on the reference sample. However, the EIS plots of E-CeMal and S-CeMal samples can be fitted with EEC in Fig. 11a in the whole immersion period, 

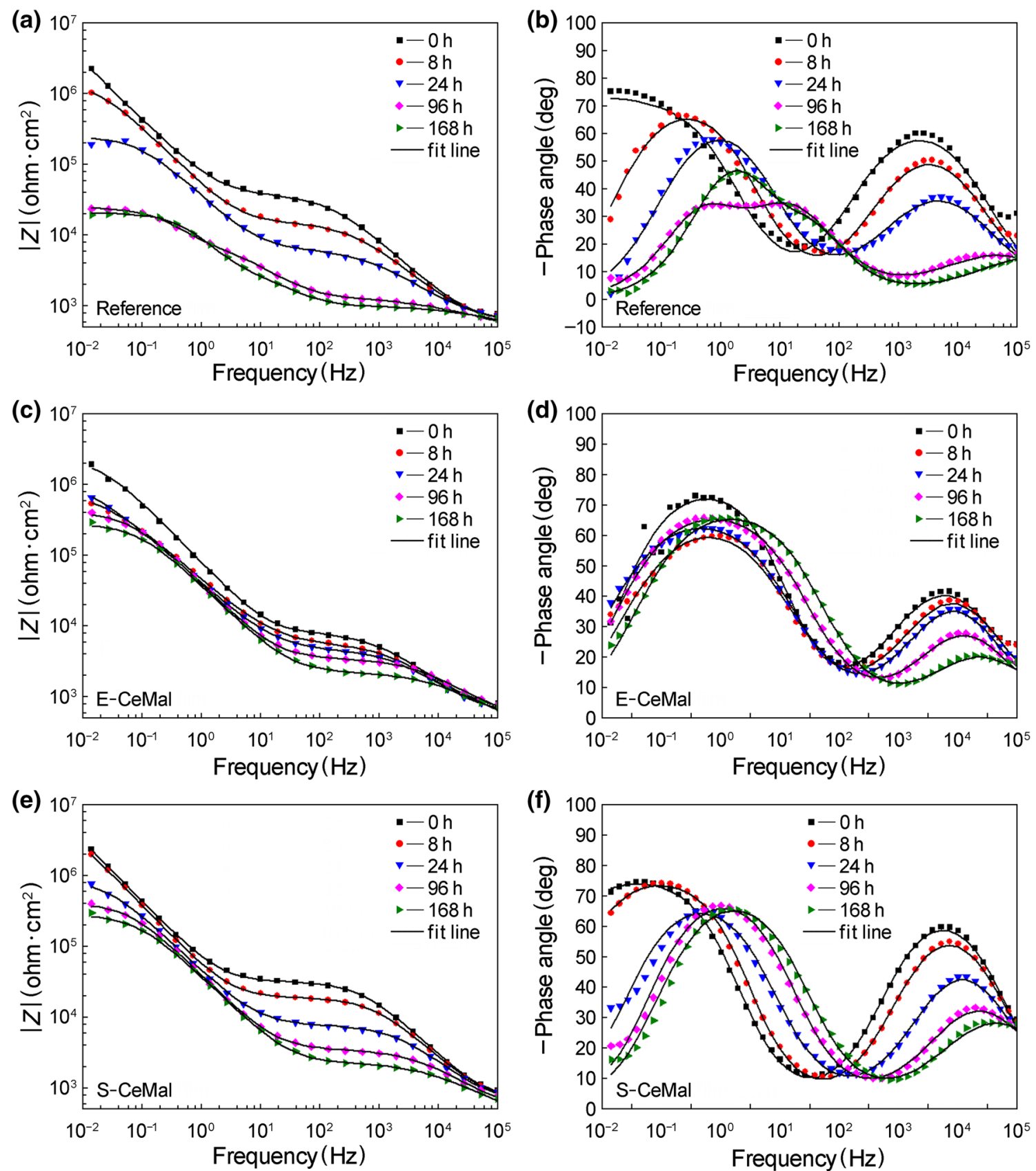

Fig. 10 Bode plots of the samples coated with $\mathbf{a}, \mathbf{b}$ reference, $\mathbf{c}, \mathbf{d}$ E-CeMal, e, $\mathbf{f ~ S - C e M a l ~ s o l - g e l ~ c o a t i n g s ~ d u r i n g ~ i m m e r s i o n ~ i n ~} 0.005 \mathrm{~mol} / \mathrm{L}$ $\mathrm{NaCl}$ solution

suggesting that AA2024-T3 is under protection. $R_{\mathrm{c}}$ is an important parameter to evaluate the protective effect of the three sol-gel coatings. The $R_{\mathrm{c}}$ values of the reference and S-CeMal samples are similar immediately after immersion $(0 \mathrm{~h})$, while the $R_{\mathrm{c}}$ value of E-CeMal sample is a little lower than the other two samples. It illustrates that the protective ability of the E-CeMal coating is a little weaker in the beginning stage. The excess CeMal in the sol-gel coating may cause more dissolution of $\mathrm{CeMal}$, which decreases the integrity of the coating. In addition, $R_{\mathrm{c}}$ value of E-CeMal sample after $8 \mathrm{~h}$ of immersion is much lower than that of S-CeMal sample after $24 \mathrm{~h}$ of immersion. This suggests that the coating with saturated CeMal can maintain effective protection for a longer period. From the $R_{\mathrm{o}}$ values, the protective ability of oxide layer between the coatings and matrix can be evaluated. The $R_{\mathrm{o}}$ values of E-CeMal and S-CeMal samples are relatively stable, indicating the formation of $\mathrm{Ce}$ oxide/hydroxide layer. From EIS results, it can be concluded that CeMal in the sol-gel coatings can provide effective protection for AA2024-T3. 

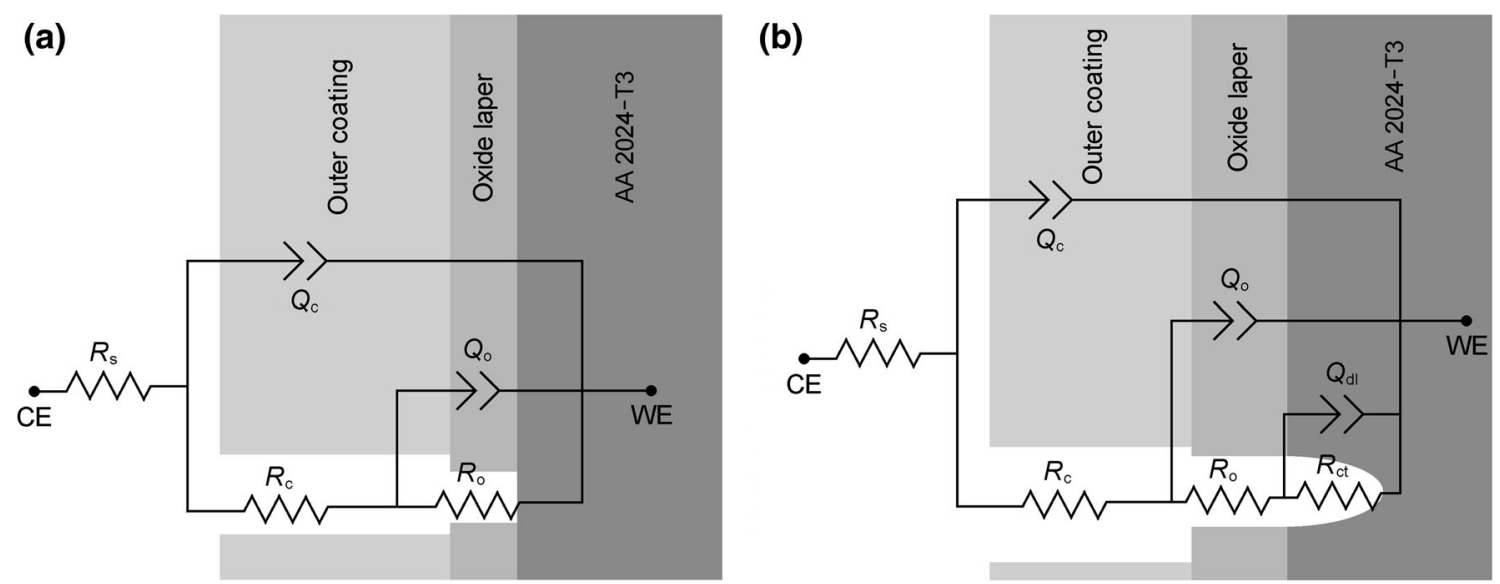

Fig. 11 Equivalent electrical circuits containing a two time constants, $\mathbf{b}$ three time constants

Table 1 Circuit parameters fitted from the EIS data of the sol-gel coatings during immersion in $0.005 \mathrm{~mol} / \mathrm{L} \mathrm{NaCl}$ solution

\begin{tabular}{|c|c|c|c|c|c|c|c|c|c|c|}
\hline Sample & Time (h) & $\begin{array}{l}R_{\mathrm{c}} \\
\left.(\mathrm{ohm} \mathrm{cm})^{2}\right)\end{array}$ & $\begin{array}{l}Q_{\mathrm{c}} \\
\left(\mathrm{S} \mathrm{cm}^{-2} \mathrm{~s}^{\mathrm{n}}\right)\end{array}$ & $n_{\mathrm{c}}$ & $\begin{array}{l}R_{\mathrm{o}} \\
\left.(\mathrm{ohm} \mathrm{cm})^{2}\right)\end{array}$ & $\begin{array}{l}Q_{\mathrm{o}} \\
\left(\mathrm{S} \mathrm{cm}^{-2} \mathrm{~s}^{\mathrm{n}}\right)\end{array}$ & $n_{\mathrm{o}}$ & $\begin{array}{l}R_{\mathrm{ct}} \\
\left.(\mathrm{ohm} \mathrm{cm})^{2}\right)\end{array}$ & $\begin{array}{l}Q_{\mathrm{dl}} \\
\left(\mathrm{S} \mathrm{cm}^{-2} \mathrm{~s}^{\mathrm{n}}\right)\end{array}$ & $n_{\mathrm{dl}}$ \\
\hline \multirow[t]{5}{*}{ Reference } & 0 & $3.81 \times 10^{4}$ & $1.25 \times 10^{-7}$ & 0.78 & $3.50 \times 10^{7}$ & $3.26 \times 10^{-6}$ & 0.80 & & & \\
\hline & 8 & $1.51 \times 10^{4}$ & $1.91 \times 10^{-7}$ & 0.75 & $1.54 \times 10^{6}$ & $4.07 \times 10^{-6}$ & 0.84 & & & \\
\hline & 24 & $6.19 \times 10^{3}$ & $5.51 \times 10^{-7}$ & 0.67 & $2.51 \times 10^{5}$ & $5.60 \times 10^{-6}$ & 0.83 & & & \\
\hline & 96 & $9.28 \times 10^{2}$ & $1.61 \times 10^{-6}$ & 0.56 & $7.45 \times 10^{3}$ & $1.14 \times 10^{-5}$ & 0.77 & $1.65 \times 10^{4}$ & $3.27 \times 10^{-5}$ & 0.85 \\
\hline & 168 & $7.53 \times 10^{2}$ & $1.34 \times 10^{-6}$ & 0.53 & $2.78 \times 10^{3}$ & $8.78 \times 10^{-6}$ & 0.84 & $1.73 \times 10^{4}$ & $1.36 \times 10^{-5}$ & 0.88 \\
\hline \multirow[t]{5}{*}{ E-CeMal } & 0 & $8.01 \times 10^{3}$ & $2.58 \times 10^{-7}$ & 0.71 & $2.22 \times 10^{6}$ & $2.33 \times 10^{-6}$ & 0.88 & & & \\
\hline & 8 & $5.29 \times 10^{3}$ & $2.36 \times 10^{-7}$ & 0.73 & $7.78 \times 10^{5}$ & $5.31 \times 10^{-6}$ & 0.76 & & & \\
\hline & 24 & $4.14 \times 10^{3}$ & $2.17 \times 10^{-7}$ & 0.74 & $1.16 \times 10^{6}$ & $5.93 \times 10^{-6}$ & 0.77 & & & \\
\hline & 96 & $2.19 \times 10^{3}$ & $3.11 \times 10^{-7}$ & 0.72 & $9.59 \times 10^{5}$ & $5.63 \times 10^{-6}$ & 0.79 & & & \\
\hline & 168 & $1.27 \times 10^{3}$ & $5.70 \times 10^{-7}$ & 0.66 & $5.42 \times 10^{5}$ & $5.30 \times 10^{-6}$ & 0.80 & & & \\
\hline \multirow[t]{5}{*}{ S-CeMal } & 0 & $3.17 \times 10^{4}$ & $4.09 \times 10^{-8}$ & 0.82 & $3.14 \times 10^{7}$ & $3.41 \times 10^{-6}$ & 0.86 & & & \\
\hline & 8 & $1.83 \times 10^{4}$ & $5.26 \times 10^{-8}$ & 0.81 & $8.95 \times 10^{6}$ & $3.86 \times 10^{-6}$ & 0.87 & & & \\
\hline & 24 & $7.27 \times 10^{3}$ & $9.64 \times 10^{-8}$ & 0.76 & $9.24 \times 10^{5}$ & $4.87 \times 10^{-6}$ & 0.82 & & & \\
\hline & 96 & $3.13 \times 10^{3}$ & $2.15 \times 10^{-7}$ & 0.71 & $4.15 \times 10^{5}$ & $5.17 \times 10^{-6}$ & 0.85 & & & \\
\hline & 168 & $1.98 \times 10^{3}$ & $3.77 \times 10^{-7}$ & 0.65 & $2.86 \times 10^{5}$ & $5.47 \times 10^{-6}$ & 0.83 & & & \\
\hline
\end{tabular}

\section{Conclusions}

1. CeMal is a new environmentally friendly inhibitor that both cerium cations and organic maleic anions can contribute to corrosion inhibition for AA2024-T3 in $0.05 \mathrm{~mol} / \mathrm{L} \mathrm{NaCl}$ solution. The protective film rapidly formed on the alloy surface when immersed in $0.05 \mathrm{~mol} / \mathrm{L} \mathrm{NaCl}$ solution with saturated CeMal. The film-forming ability of cerium cations was greatly enhanced by mixing with organic maleic anion part.

2. The sol-gel coating using the acetic acid solution saturated with CeMal as precursor can provide effective protection for AA2024-T3, as revealed by the higher corrosion resistance than that of other sol-gel coatings from EIS during the immersed period.
Acknowledgements The authors acknowledge the financial support from the National Natural Science Foundation of China (Grant Nos. 51571202 and 51001109).

\section{References}

[1] C. Lee, T. So, K. Shin, Acta Metall. Sin. (Engl. Lett.) 29, 638 (2016)

[2] A.E. Hughes, A. Boag, A.M. Glenn, D. McCulloch, T.H. Muster, C. Ryan, C. Luo, X. Zhou, G.E. Thompson, Corros. Sci. 53, 27 (2011)

[3] D. Snihirova, S.V. Lamaka, P. Taheri, J.M.C. Mol, M.F. Montemor, Surf. Coat. Technol. 303, 342 (2016)

[4] B.R.W. Hinton, J. Alloys Compd. 180, 15 (1992)

[5] O. Lopez-Garrity, G.S. Frankel, J. Electrochem. Soc. 161, C95 (2014) 
[6] M. Moradi, Z.L. Song, T. Xiao, J. Mater. Sci. Technol. 34, 2447 (2018)

[7] R.B. Vignesh, T.N.J.I. Edison, M.G. Sethuraman, J. Mater. Sci. Technol. 30, 814 (2014)

[8] P. Visser, H. Terryn, J.M.C. Mol, Corros. Sci. 140, 272 (2018)

[9] S.K. Yan, G.L. Song, Z.X. Li, H.N. Wang, D.J. Zheng, F.Y. Cao, M. Horynova, M.S. Dargusch, L. Zhou, J. Mater. Sci. Technol. 34, 421 (2018)

[10] Y.M. Li, G.R. Zhao, Y.H. Qian, J.J. Xu, M.S. Li, J. Mater. Sci. Technol. 34, 466 (2018)

[11] W. Zhang, R.G. Buchheit, Corrosion 59, 356 (2003)

[12] L.B. Coelho, M. Taryba, M. Alves, M.F. Montemor, M.G. Olivier, Electrochim. Acta 277, 9 (2018)

[13] B.R.W. Hinton, D.R. Arnott, Microstruct. Sci. 17, 311 (1989)

[14] D.R. Arnott, N.E. Ryan, B.R.W. Hinton, B.A. Sexton, A.E. Hughes, Appl. Surf. Sci. 22-23, 236 (1985)

[15] I.V. Gordovskaya, T. Hashimoto, J. Walton, M. Curioni, G.E. Thompson, P. Skeldon, J. Electrochem. Soc. 161, C601 (2014)

[16] A.J. Aldykewicz Jr., H.S. Isaacs, A.J. Davenport, J. Electrochem. Soc. 142, 3342 (1995)

[17] P. Rodič, I. Milošev, J. Electrochem. Soc. 163, C85 (2016)

[18] A.J. Davenport, H.S. Isaacs, M.W. Kendig, Corros. Sci. 32, 653 (1991)

[19] H.W. Shi, E.H. Han, S.V. Lamaka, M.L. Zheludkevich, F.C. Liu, M.G.S. Ferreira, Prog. Org. Coat. 77, 765 (2014)

[20] M.F. Montemor, Surf. Coat. Technol. 258, 17 (2014)

[21] J. Mardel, S.J. Garcia, P.A. Corrigan, T. Markley, A.E. Hughes, T.H. Muster, D. Lau, T.G. Harvey, A.M. Glenn, P.A. White, S.G. Hardin, C. Luo, X. Zhou, G.E. Thompson, Prog. Org. Coat. 70, 91 (2011)

[22] S.A.S. Dias, S.V. Lamaka, T.C. Diamantino, M.G.S. Ferreira, J. Electrochem. Soc. 161, C215 (2014)

[23] S. Kallip, A.C. Bastos, K.A. Yasakau, M.L. Zheludkevich, M.G.S. Ferreira, Electrochem. Commun. 20, 101 (2012)
[24] M. Forsyth, C.M. Forsyth, K. Wilson, T. Behrsing, G.B. Deacon, Corros. Sci. 44, 2651 (2002)

[25] S.J. Garcia, T.A. Markley, J.M.C. Mol, A.E. Hughes, Corros. Sci. 69, 346 (2013)

[26] H.W. Shi, E.H. Han, F.C. Liu, Corros. Sci. 53, 2374 (2011)

[27] T.H. Hu, H.W. Shi, W. Tao, F.C. Liu, S.H. Fan, E.H. Han, Corros. Sci. 95, 152 (2015)

[28] G. Bereket, A. Yurt, Corros. Sci. 43, 1179 (2001)

[29] H.W. Shi, E.H. Han, F.C. Liu, S. Kallip, Appl. Surf. Sci. 280, 325 (2013)

[30] E. Wiberg, A.F. Holleman, Inorganic Chemistry (Elsevier, Amsterdam, 2001). ISBN 0-12-352651-5

[31] D.K. Heller, W.G. Fahrenholtz, M.J. O’Keefe, Corros. Sci. 52, 360 (2010)

[32] N. Petrova, D. Todorovsky, S. Angelova, D. Mehandjiev, J. Alloys Compd. 454, 491 (2008)

[33] C. Thee, L. Hao, J.H. Dong, X. Mu, W. Ke, Acta Metall. Sin. (Engl. Lett.) 28, 261 (2015)

[34] Y.Y. Song, H.W. Shi, J. Wang, F.C. Liu, E.H. Han, W. Ke, G.X. Jie, J. Wang, H.J. Huang, Acta Metall. Sin. (Engl. Lett.) 30, 1201 (2017)

[35] C.J. Huang, W.Y. Li, Y.C. Xie, M.P. Planche, H.L. Liao, G. Montavon, J. Mater. Sci. Technol. 33, 338 (2017)

[36] J.L. Wang, W. Yang, D.P. Xu, X.F. Yao, Acta Metall. Sin. (Engl. Lett.) 30, 1109 (2017)

[37] D.V. Mashtalyara, S.V. Gnedenkov, S.L. Sinebryukhov, I.M. Imshinetskiy, A.V. Puz', J. Mater. Sci. Technol. 33, 461 (2017)

[38] M.L. Zheludkevich, R. Serra, M.F. Montemor, K.A. Yasakau, I.M. Miranda Salvado, M.G.S. Ferreira, Electrochim. Acta 51, 208 (2005)

[39] B. Xue, M. Yuz, J.H. Liu, S.M. Li, L.L. Xiong, X.X. Kong, J. Electrochem. Soc. 163, C798 (2016)

[40] J.C. Li, B. Hurley, R. Buchheit, J. Electrochem. Soc. 162, C563 (2015) 